\title{
Características farmacológicas de las drogas recreativas (MDMA y otras anfetaminas, Ketamina, GHB, LSD y otros alucinógenos)
}

\author{
Pedro Lorenzo Fernández, Ignacio Lizasoain Hernández
}

Departamento de Farmacología. Facultad de Medicina. Universidad Complutense de Madrid

Enviar correspondencia: Prof. P Lorenzo. Departamento de Farmacología. Facultad de Medicina. Universidad Complutense de Madrid. 28040 Madrid. Tfno./Fax. 91-394-1478. E-mail: pedrolor@med.ucm.es

\begin{abstract}
Resumen
En este capítulo hacemos una revisión de las características farmacológicas de las principales drogas recreativas englobadas en 2 grupos: drogas de diseño y alucinógenos.

Las drogas de diseño (término acuñado por G Henderson) comprenden: el grupo de los derivados de las feniletilaminas (derivados de anfetaminas) como el MDMA (éxtasis), el grupo de los opiáceos sean derivados del fentanilo o de la meperidina, el grupo de las arilhexilaminas como la fenciclidina (PCP), el grupo de los derivados de la metacualona y otras drogas de diseño con el gamma-hidroxi-butirato -GHB-, el extasis vegetal y otros. Por otra parte se revisan los principales alucinógenos, centrándonos en el LSD. El MDMA (3,4,-metilenodioximetanfetamina) es la droga de diseño más importante por su elevado consumo, posee acciones estimulantes y alucinógenas y puede producir neurotoxicidad. El GHB, la ketamina y una benzodiacepina como el flunitrazepam forman un grupo nuevo de drogas llamadas "drogas de violación por cita" ya que al ser depresores del sistema nervioso central y por sus propiedades incoloras, inodoras e insípidas producen efectos en la víctima de incapacidad para prevenir una agresión sexual. La LSD (dietilamida del ácido lisérgico) es la principal droga alucinógena y es una de las drogas con mayor potencia farmacológica.
\end{abstract}

Palabras claves: drogas de diseño, drogas de violación por cita, GHB, ketamina, LSD, MDMA.

\section{Summary}

In this chapter we have studied the pharmacological properties from the main so-called "club drugs". We have divided these drugs into 2 groups: "designer drugs" and hallucinogen drugs. "Designer drugs" (term coined by G Henderson) include: phenylethylamines such as MDMA ("ecstasy"), opioids such as meperidine and fentanyl derivatives, phencyclidine (PCP), metaqualone-like compounds and other drugs such as gamma hydroxybutyrate (GHB). MDMA (3-4 methylenedioxymethamphetamine) is a synthetic, psychoactive drug with both stimulant and hallucinogenic properties which might produce neurotoxicity. GHB and ketamine are predominantly central nervous system depressants. GHB, ketamine and flunitrazepam (a classic benzodiazepine) constitute a new class of drugs called "date rape drugs" since they are often colorless, tasteless, odorless and they can incapacitate victims and prevent them from resisting sexual assault. LSD (lysergic acid diethylamide) is the most potent hallucinogenic drug and produces significant psychodelic effects.

Key Words: "Date rape drugs," "Designer drugs", GHB, ketamine, LSD, MDMA. 


\section{CONCEPTOY CLASIFICACIÓN}

$\mathbf{L}$ a expresión "drogas de diseño" fue introducida en los años 1960s por un farmacéutico californiano, Gary Henderson, refiriéndose a un conjunto de nuevas drogas de abuso obtenidas con fines recreativos y diseñadas y elaboradas clandestinamente para escapar de restricciones legales. Su irrupción en España tuvo lugar al final de los años 1980s. Se trata de sustancias estructural y farmacológicamente semejantes a sustancias controladas mediante Tratados
Internacionales (psicoestimulantes, alucinógenos, etc.).

Al no ser sus acciones idénticas a las sustancias controladas legalmente, la mayoría no están específicamente incluidas en las Listas Anexas de los Convenios que fiscalizan los llamados estupefacientes y psicotropos.

Las principales "drogas de diseño" están comprendidas en varios grupos farmacológicos: feniletilaminas (derivados de anfetaminas), opiáceos (derivados de fentanilo y meperidina), arilhexilaminas (fenciclidina) y análogos y derivados de metacualona y otros (Tabla I).

\section{1.- FENILETILAMINAS:}

\section{Tabla I. Clasificación de las "Drogas de diseño"}

Metanfetamina crystal, meth

TMA-2 (2,4,5-trimetoxi anfetamina)

DOM (4-metil-2,5 dimetoxi anfetamina) STP

PMA (parametoxi anfetamina)

DOB (4-bromo-2,5-dimetoxi anfetamina)

2CB-MFT (4-bromo-2,5-dimetoxifenil anfetamina) afterturner

MDA (3,4-metilenodioxi anfetamina) love drug

MDMA (3,4-metilenodioxi metanfetamina) éxtasis, Adán, M\&M.

MDEA (3,4-metilenodioxi etilanfetamina) Eva

\section{OTROS ANALOGOS DE FENILETILAMINA}

* 4-BROMO-2,5-DIMETOXIFENETILAMINA (análogo de DOB)

* 4-ETOXI-2,5-DIMETOXIANFETAMINA (2,4,5 MEM) (análogo del STP)

* 4,5-DIHIDRO-4-METIL-5-FENIL-2-OXAZOLAMINA (4-metilaminorex)

*3,4-METILENEDIOXI-N-N-DIMETILANFETAMINA (N,N-dimetilMDA) (análogo de MDA y MDMA)

* N,N-DIMETILANFETAMINA (N,N-DMA)

* 4-TIOMETIL-2,5-DIMETOXIANFETAMINA (para-DOT) (análogo de TMA-2)

* PARA-METOXIMETANFETAMINA (PMMA) (análogo de PMA)

\section{2.- OPIACEOS}

\section{Derivados del Fentanilo:}

AMF (alfametil fentanilo) China white

3MF (3 metil fentanilo)

PFF (parafluoro fentanilo)

AMAF (alfametilacetil fentanilo)

Derivados de la Meperidina:

MPPP (1 metil, 4 fenil, 4 propionoxipiperidina)

MPTP (1 metil, 4 fenil, 1,2,3,6 tetrahidropiridina)

\section{3.- ARILHEXILAMINAS:}

Fenciclidina (PCP) angel dust

PCC (piperidino ciclohexano carbonitrilo)

TCP (tiofeno fenciclidina)

PCE (n-etil fenciclidina)

PHP (fenilciclohexilpirrolidina)

\section{4.- DERIVADOS DE LA METACUALONA:}

Meclocualona

Nitrometacualona

5.- OTROS: Gamma-Hidroxi-Butirato (GHB), Extasis vegetal, etc. 


\section{FENILETILAMINAS.}

\subsection{MDMA (3,4-metilenodioximetanfeta- mina)}

La más importante de las "drogas de diseño" derivadas de feniletilaminas es la MDMA, por lo extendido de su consumo y por las numerosas investigaciones llevadas a cabo sobre su farmaco-toxicología.

No se conoce ni el nombre del químico ni la fecha en la que se sintetizó la MDMA. El primer documento público referente a la preparación y propiedades de esta droga corresponde a una patente alemana solicitada por la firma E. Merck en 1912 y otorgada en 1914. Desde su aparición en el mercado ilícito de la droga han aparecido numerosas publicaciones que demostraron que la administración sistémica de MDMA a diversas especies animales causa una selectiva y pronunciada disminución en diversos marcadores de la función serotonérgica central.
En España las drogas de diseño llegaron a mediados de los años 1980s. Los aspectos epidemiológicos sobre el consumo de MDMA se recogen en el capítulo 4 de esta monografía1.

Desde hace varios años la mayor parte del interés científico sobre la MDMA está orientado a la investigación de su neurotoxicidad.

\subsubsection{Química}

La MDMA (3,4-metilenodioximetanfetamina) es una base sintética derivada de la feniletilamina y relacionada estructuralmente con la sustancia estimulante psicomotora anfetamina y la sustancia alucinógena mescalina, compartiendo propiedades de ambos compuestos (Fig. 1). El isómero dextro es la forma farmacológicamente más activa.

Entre los sinónimos químicos destacan entre otros los siguientes: N-metil-3,4-metilenodioxianfetamina, $\mathrm{N}$-alfa-dimetil-3,4-metilenodioxifenetilamina; N-alfa-dimetil-homopipe-

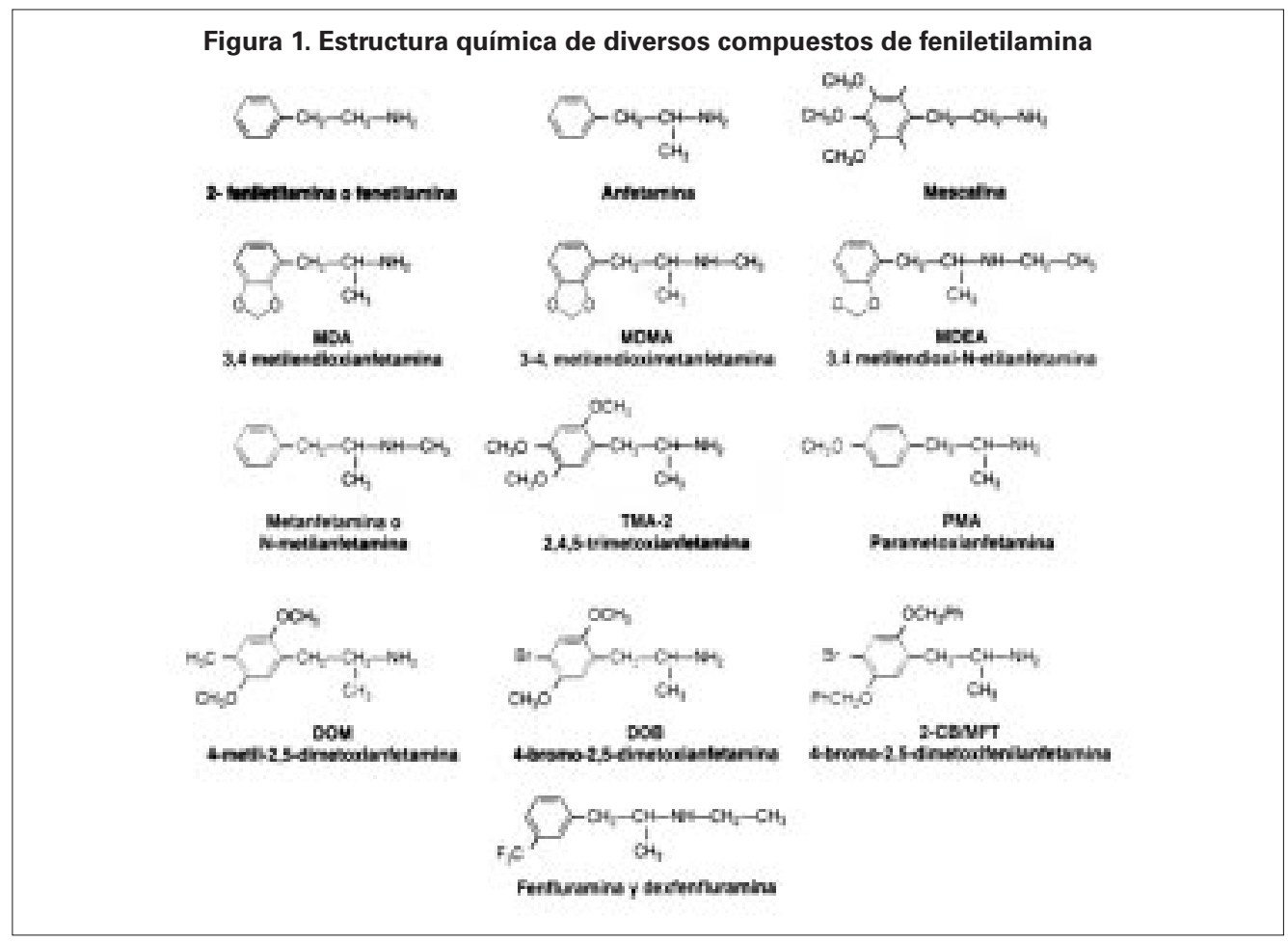


ronilamina,2-metilamina-1-(3,4-metilenodioxifenil)-propano, N-metil-1-(3,4-metilenodioxifenil)-2-aminopropano, N-alfa-dimetilbeta-(3,4metilenodioxifenil)-etilamina, $\mathrm{N}$-alfa-dimetilbenzodioxol-5-etilamina.

Su denominación callejera más popular es la de "EXTASIS" (ECSTASY), XTC; también MDM y M\&M. En Europa suele denominarse "E". El nombre de ADAN es más frecuente en el ámbito de la psicología clínica.

\subsubsection{Farmacocinética}

La MDMA se absorbe muy bien por todas las vías de administración, si bien su eficacia farmacológica parece ser mayor cuando se administra por vía parenteral, según las investigaciones llevadas a cabo en distintas especies animales. Atraviesa bien las barreras orgánicas por su liposolubilidad y especialmente la barrera hemato-encefálica; de ahí sus manifiestos efectos sobre SNC.

El metabolismo de la MDMA ha sido estudiado ampliamente in vivo e in vitro en varias especies animales, siendo de particular interés por la posible implicación de algunos de sus metabolitos en sus acciones farmacológicas y tóxicas.

En la rata, la MDMA se metaboliza por procesos de N-desmetilación, O-dealquilación, desaminación, hidroxilación aromática y posterior glucurono- y sulfoconjugación, habiéndose obtenido hasta 17 metabolitos distintos que se eliminan en su mayor parte por la orina. Uno de sus metabolitos más importantes obtenido por N-desmetilación de la MDMA, es la MDA (metilenodioxianfetamina), a la que se considera parcialmente responsable de la neurotoxicidad de la MDMA.

La DHMA (3-4 dihidroximetanfetamina) y la 6OH-MDMA (2-hidroxi-4-5-metilenodioximetanfetamina) son otros metabolitos de la MDMA aislados en cerebro de rata después de la administración de MDMA, pero no inducen neurotoxicidad en los terminales nerviosos serotonérgicos y dopaminérgicos.

La enzima responsable de desmetilar la MDMA para formar DHMA es la CYP2D6.
Esta enzima presente en hígado y cerebro de muchas especies animales y de la especie humana es una isoenzima genéticamente polimorfa de la familia citocromo P-450. Algunas etnias (caucasianos 5-10\%) carecen de ésta enzima como consecuencia hereditaria de mutaciones genéticas autosómicas recesivas. Los individuos pertenecientes a ésta población metabolizarían más lentamente la MDMA, lo que podría condicionar en ellos la toxicidad de la droga en fase aguda.

\subsubsection{Acciones farmacológicas}

Los primeros estudios farmacológicos acerca de los efectos de la MDMA sobre el Sistema Nervioso Central y la conducta animal fueron descritos en un estudio general sobre toxicidad llevado a cabo en la Universidad de Michigan en 1953. En este estudio toxicológico llevado a cabo en perros y monos, se observó que la inyección intravenosa de MDMA producía convulsiones, rigidez y temblor, y actitudes grotescas de los animales con un comportamiento interpretado como análogo al de las alucinaciones así como un conjunto de signos característicos de la estimulación simpática: midriasis, piloerección, hipertermia y aumento de la frecuencia cardiaca.

Estos estudios previos sobre la farmacología de la MDMA fueron seguidos de otros muchos, tanto en animales de experimentación como en humanos. Las acciones farmacológicas de la MDMA en humanos, se fueron conociendo en la mayoría de los casos por los datos observados en los consumidores de la droga con fines recreativos.

\subsubsection{Efectos subjetivos.}

El efecto de MDMA más señalado por los consumidores es la capacidad de ésta droga para inducir un determinado estado emocional caracterizado por la empatía, es decir una participación afectiva con reconocimiento intelectual y emocional de los pensamientos, sentimientos y comportamientos del otro, incluso de los que son perturbadores, pudien- 
do existir o no una situación de simpatía, es decir, de coparticipación de sus comportamientos. Esta sensación de positiva sensualidad (no sexualidad), y euforia vitalista, parece estar condicionada por dos factores: edad y frecuencia de administración de la droga.

La edad es un claro factor condicionante del deseo de esta droga. A su vez, la frecuencia de uso y la dosis también condicionan sus efectos como droga recreativa. Tomar doble dosis no supone experimentar el doble de efectos positivos, sino que existe un aumento del disconfort y de los efectos negativos. Los consumidores de MDMA durante periodos prolongados de tiempo han descrito frecuentemente un incremento de sensaciones desagradables y prolongados periodos de "burn out." Los más "expertos" recomiendan guardar intervalos de 2 ó 3 semanas entre dosis.

\subsubsection{Efectos entactógenos.}

Se ha sugerido que la MDMA y las sustancias que poseen efectos psico-farmacológicos semejantes a los de esta droga, son miembros de una misma familia farmacológica, denominados entactógenos. Se pueden definir los entactógenos como sustancias que al tener efectos empáticos, facilitando las relaciones interpersonales, son capaces de facilitar el acceso al interior de la conciencia del individuo, para un mejor control de los conflictos emocionales, pareciendo especialmente útil esta propiedad en terapias psicoanalíticas. Los fármacos entactógenos son distintos a los denominados estimulantes centrales (prototipo anfetamina) o a los alucinógenos (prototipo la anfetamina metoxilada DOM). Esta diferencia ha sido puesta de manifiesto en estudios de radioelectroencefalografía, de relación estructura-actividad y por diferencias bioquímicas.

\subsubsection{Efectos simpaticomiméticos}

Al ser la MDMA un derivado estructural de anfetamina, es capaz de producir efectos simpaticomiméticos de tipo anfetamínico.
Los efectos de la estimulación simpática son: taquicardia, arritmias, hipertensión y efectos neurológicos y psíquicos: midriasis, piloerección, hipertermia, trismo, temblores, parestesias, hiperreflexia, bruxismo, insomnio y anorexia por activación adrenérgica y serotonérgica.

\subsubsection{Efectos de tipo alucinatorio}

Los más importantes son alteraciones de la percepción visual: visión borrosa, cromatismo visual y alteraciones de la percepción temporal y de la percepción táctil.

Estos efectos no son propiamente alucinatorios, ya que en la alucinación hay una percepción sin objeto a percibir. Se trata de alteraciones perceptivas, que algunos autores denominan alteraciones de tipo alucinatorio.

En estudios de discriminación de drogas la MDMA ejerce una significativa actividad de tipo estimulante, pero poca o ninguna actividad alucinógena, ya que en este tipo de ensayos puede sustituir completamente a la $\mathrm{d}$ anfetamina y cocaína, parcialmente al LSD y no sustituye al DOM (4-metil-2-5-dimetoxianfetamina), un alucinógeno muy potente.

\subsubsection{Efectos reforzadores positivos.}

Si bien la MDMA no puede considerarse una droga adictógena en humanos y no desecadena, al suprimir su administración, un síndrome de abstinencia típico, en tests de autoadministración en animales, éstos tienden a administrarse MDMA, lo que concuerda con la tendencia al uso recreativo de la droga en humanos. Los primates (babuino y macacus rhesus) condicionados a autoadministrarse cocaína, también son capaces de autoadministrarse MDMA.

En experimentos de autoestimulación intracraneal, la administración previa de MDMA desciende el umbral de estimulación. Asimismo, en experimentos con ratas sometidas al test de preferencia condicionada de lugar, éstos animales resultan positivamente condicionados. Estos hechos demuestran 
que la MDMA es capaz de producir refuerzo positivo al menos a nivel experimental.

Sin embargo, de los resultados de los estudios clínicos no se puede deducir que la MDMA tenga el patrón tipo de las drogas dependígenas, ya que no existe en los consumidores ni dependencia física (síndrome de abstinencia), ni dependencia psicológica (deseo compulsivo de consumir la droga), aunque sí existen datos que confirman tolerancia farmacológica en algunos consumidores, ya que necesitan incrementar la dosis para conseguir los efectos subjetivos iniciales.

\subsubsection{Efectos adversos:}

\section{a.- Toxicidad aguda.}

Aparte de otras reacciones adversas ya descritas, los efectos tóxicos agudos más relevantes relacionados con el consumo de MDMA, aunque de intensidad variable según la dosis son: hipertensión arterial, arritmias cardiacas, asistolias, colapso cardiovascular, coagulación intravascular diseminada, rabdomiolisis, insuficiencia renal aguda, cuadros de espasticidad muscular, convulsiones así como manifestaciones de hepatotoxicidad e hipertermia.

El éxtasis se ha visto involucrado en varios casos de hepatitis aguda de gravedad variable y de mecanismo probablemente idiosincrático, relacionado con el efecto de algún metabolito generado en el hígado y no identificado, quizá debido a la citada deficiencia metabólica de la enzima poliforma CYP2D6 que ocurre en al menos en un $5 \%$ de la población de etnia caucásica y que diese lugar a la formación de un metabolito hepatotóxico. Ante un paciente joven con hepatitis aguda no vírica, de origen no filiado, hay que sospechar un posible consumo de MDMA aunque haya sido ocasional. La recaída en el consumo de la droga después de un episodio de hepatotoxicidad puede ocasionar una fibrosis hepática acelerada.

La hipertermia puede verse agravada por el ambiente caldeado de las discotecas (raves), donde se consumen las pastillas de éxtasis; a este ambiente se suma la hiperactividad de los consumidores, que bajos los efectos de la psicoestimulación bailan y se agitan durante horas reponiendo la pérdida de líquido a base de agua. En estas condiciones puede desencadenarse un cuadro de "golpe de calor", que requiera tratamiento urgente. Dosis elevadas pueden precipitar la muerte por fibrilación ventricular o hemorragias intracraneales.

Estos cuadros tóxicos pueden ir acompañados de alteraciones analíticas tales como: leucocitosis, hiperglucemia, aumento de creatinfosfoquinasa (CPK), alteraciones iónicas, aumento del nitrógeno ureico en sangre y otras alteraciones metabólicas.

Una costumbre que encierra un peligro adicional es asociar el consumo de éxtasis con la ingestión de alcohol, con la finalidad de atenuar los efectos excitantes del éxtasis y aumentar la resistencia al consumo de esta droga. Esta asociación del alcohol con MDMA, así como con cualquier droga psicotropa, puede dar lugar a reacciones imprevisibles incluidos estados comatosos, colapso y muerte.

Aunque la MDMA puede ocasionar numerosos efectos indeseables, la aparición de reacciones tóxicas muy graves no es frecuente, y en la mayoría de los casos los diagnósticos clínicos sobre la toxicidad de la MDMA no han sido confirmados con análisis toxicológicos. También se han descrito reacciones anómalas como consecuencia de interacciones farmacológicas o debidas a complicaciones de los efectos simpaticomiméticos de la MDMA por sobredosis o posiblemente por reacciones idiosincráticas.

Son raros los casos de fallecimiento directamente atribuibles a la MDMA, sobre todo si se considera que el consumo de esta droga está muy extendido en el mundo occidental. Sin embargo, no se debe olvidar la posibilidad de muerte súbita debido a una sobredosificación relativa en individuos con déficit de la enzima responsable del metabolismo de la MDMA (CYP2D6) de la familia citocromo P450. Ya hemos señalado que al menos que un $5 \%$ de individuos de etnia caucasiana carecen de esta enzima por mutaciones genéticas hereditarias y puede reaccionar a 
"dosis normales" de la droga con reacciones tóxicas muy graves, incluida la muerte.

Otras veces la muerte se debió a accidentes (automovilísticos o laborales) por los efectos de la droga sobre la capacidad de atención y concentración de los consumidores y por las alteraciones en la percepción visual de objetos y colores durante la noche.

Las consecuencias a largo plazo producidas por el consumo de MDMA todavía son poco conocidas en humanos y los datos experimentales de que se dispone hasta ahora, indican que la MDMA es neurotóxica en diversas especies animales.

Además de la toxicidad intrínseca de la MDMA hay que tener en cuenta una toxicidad adicional, la de las sustancias añadidas para adulterar la droga, en muchos casos muy tóxicas y que contaminan su pureza química, sin olvidar que en la síntesis clandestina de las drogas de diseño se utilizan precursores no controlados que son, en algunos casos, más tóxicos que la propia droga. El tratamiento de la intoxicación aguda por MDMA es el común al de los derivados anfetamínicos.

El tratamiento de la intoxicación aguda por MDMA debe ser urgente e incluye medidas como lavado gástrico, administración de carbón activado, diuresis forzada ácida (los derivados anfetamínicos son compuestos alcalinos) además de medidas farmacológicas para el tratamiento de las complicaciones (alfa y beta-bloqueantes, antagonistas del calcio, neurolépticos, benzodiacepinas y bloqueantes neuromusculares). Sin olvidar la utilización de métodos físicos o farmacológicos para disminuir la temperatura corporal del individuo.

\section{b. Neurotoxicidad serotoninérgica.}

La toxicidad más importante que produce a largo plazo la MDMA y de la que cada vez existe más evidencia científica, es un efecto neurotóxico selectivo sobre el sistema serotoninérgico del cerebro de la rata. Este efecto se observa también en el primate no humano aunque se acompaña, como se ha demostra- do recientemente, por una degeneración del sistema dopaminérgico.

En la mayoría de los trabajos científicos sobre la neurotoxicidad serotoninérgica de la MDMA se evalúa ésta por alteraciones observadas en 4 marcadores bioquímicos: 1) concentración de serotonina (5HT) en las vesículas de terminales nerviosos serotonérgicos, 2) concentración del principal metabolito de la $5 \mathrm{HT}$, el ácido 5-hidroxiindolacético (5HIAA), 3) actividad de la enzima triptófanohidroxilasa (TPH), factor limitante de la síntesis de $5 \mathrm{HT}$, en varias estructuras cerebrales y 4) densidad de los lugares de recaptación de la $5 \mathrm{HT}$ en los terminales nerviosos serotonérgicos. Son numerosos los datos experimentales obtenidos que indican alteraciones bioquímicas y estructurales en el sistema serotonérgico.

Estas alteraciones neuroquímicas, selectivas del sistema serotoninérgico, van acompañadas de alteraciones estructurales de las neuronas serotonérgicas (axones y nervios) puestas de manifiesto por métodos inmunohistoquímicos, autorradiográficos, etc. (Fig. 2).

\section{c. Neurotoxicidad dopaminérgica.}

Sin bien la neurotoxicidad serotoninérgica es la más demostrada en numerosos trabajos de investigación y de la que hay mayor evidencia en primates no humanos y en la rata, últimas investigaciones llevadas a cabo por G. Ricaurte en el año 2002 en la Facultad de Medicina de la Universidad John Hopkins de Baltimore, en monos ardilla y en babuinos pusieron de manifiesto que la administración de 2 ó 3 dosis secuenciales de MDMA en estos animales equivalentes a las consumidas por los adultos con fines recreativos, producían un deterioro de las neuronas dopaminérgicas en el cerebro con manifestaciones parkinsonianas. Dada la semejanza filogénica de los primates con la especie humana, no es aventurado pensar que los individuos consumidores de MDMA tengan mayor riesgo de desarrollar un síndrome parkinsoniano a medida que se vayan haciendo mayores, a lo que también contribuiría el hecho de que la dotación de dopamina en el cerebro va sien- 
Figura 2. Corteza somatosensorial de macaco. En los animales tratados con MDMA se observa una significativa disminución de los axones serotonérgicos, particularmente en las capas corticales profundas. Barra $=100 \mu \mathrm{m}$. (Wilson y cols. 1989, con permiso)

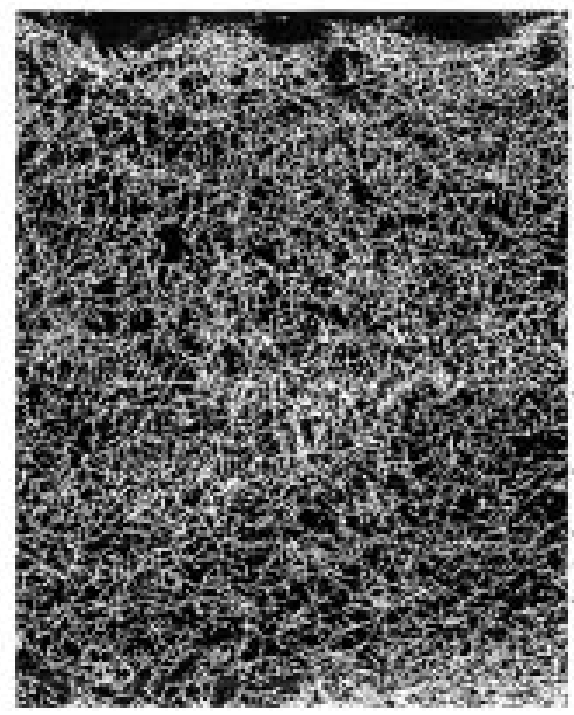

CONTROL

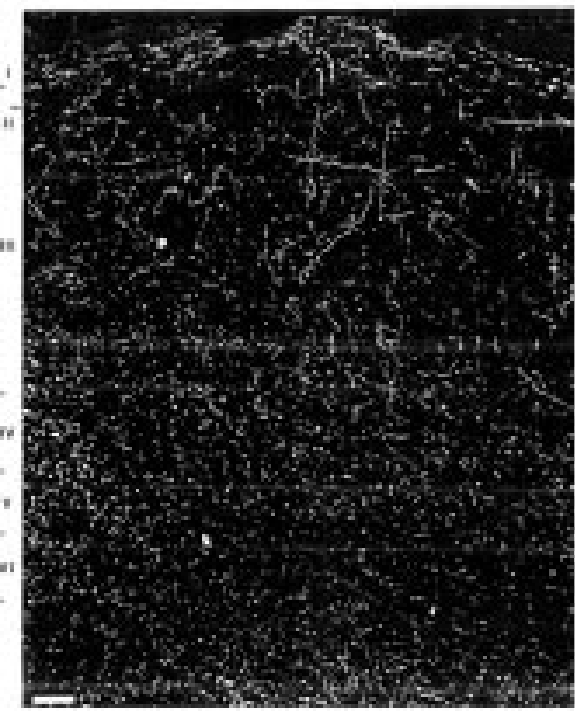

MDMA do menor a medida que avanza la edad. Esta disminución de la actividad neuronal dopaminérgica unida a la reducción ya conocida de la actividad serotoninérgica, contribuiría al desarrollo de manifestaciones de vejez prematura desde el punto de vista neuropsicológico.

\section{d. Mecanismos de neurotoxicidad}

A pesar de que está bien establecido de que la MDMA es capaz de producir neurodegeneración selectiva de las neuronas serotonérgicas, los mecanismos de acción subyacentes no han sido claramente identificados. Se sugieren, no obstante, varias posibles hipótesis que podrían explicar esta neurotoxicidad: formación de un metabolito tóxico de MDMA, de 5HT y de dopamina (DA), formación de radicales libres, elevación de la temperatura, entre otros.

El principal metabolito de la MDMA es la MDA (píldora del amor), metabolito selectivamente neurotóxico en neuronas serotonérgi- cas y que pudiera ser responsable, bien por sí mismo, o dando lugar a otro metabolito neurotóxico, de la neurotoxicidad de la MDMA.

Se ha considerado la posibilidad de que la $5 \mathrm{HT}$ liberada inmediatamente después de la administración de MDMA, se oxidara a una neurotoxina como la 5-6 ó 5-7-dihidroxitriptamina, encontradas en cerebro de rata tras la administración de anfetaminas sustituidas.

La DA ha sido considerada como posible mediador de la neurotoxicidad producida por MDMA, pues si bien se considera esta droga como neurotóxica selectiva serotonérgica, facilita la liberación aguda de DA y parece existir una relación entre la presencia de DA y la neurotoxicidad de la MDMA. Se ha demostrado que la L-DOPA, precursor de DA, potencia la neurotoxicidad de la MDMA mientras que la inhibición de la síntesis o liberación de DA, la atenúa. Quizá un exceso de DA, podría dar lugar a productos de oxidación (6-OH-DA) u otros metabolitos neurotóxicos. 
La formación de especies reactivas de oxígeno (radicales hidroxilo) y nitrógeno (óxido nítrico) procedentes del metabolismo de la MDMA y la existencia de un proceso de estrés oxidativo que conduce a un aumento del grado de peroxidación lipídica neuronal es una teoria postulada por numerosos autores como uno de los mecanismos de la neurotoxicidad serotonérgica.

La temperatura corporal es una variable importante que pudiera estar relacionada con la neurotoxicidad inducida por MDMA. Se sabe que la MDMA, como otras anfetaminas, eleva la temperatura corporal central. Es más, si esta elevación de la temperatura es atenuada, tanto farmacológica como ambientalmente, la neurotoxicidad por MDMA se atenúa. Por el contrario, si se eleva la temperatura corporal central (por aumento de la temperatura ambiente) la neurotoxicidad por MDMA se incrementa.

Conviene recordar que los estudios en animales de experimentación indican que incluso el consumidor ocasional de MDMA puede tener riesgo de desarrollar neurotoxicidad cerebral. Esta posibilidad aumenta a medida que se aumenta la dosis administrada o se aumenta el número total de dosis, considerándose como probable el riesgo de neurotoxicidad por el consumo frecuente de la droga con fines recreativos. Los sujetos que consumen varias dosis (6 ó mas) cada noche en los "raves" tienen alto riesgo de neurotoxicidad y este riesgo aumenta si frecuentan estos "raves" varias veces por semana. Parece demostrado que sujetos consumidores de MDMA con predisposición a padecer problemas neuropsiquiátricos o con antecedentes personales o familiares de ansiedad, depresión o psicosis tienen un mayor peligro potencial de desarrollar procesos psiquiátricos crónicos.

Por otra parte, existe la posibilidad de que los consumidores "asintomáticos" de MDMA comienzen a experimentar síntomas neuropsíquicos relacionados con la droga a medida que aumente su edad. Como las funciones serotonérgica y dopaminérgica varían con la edad, es posible que la "reserva" de éstas neuronas funcionales disminuya y que los síntomas de neurotoxicidad se desenmascaren. Como dijo Charles Schuster, siendo Director del NIDA (National Institute of Drug Abuse): "No sabemos si los jóvenes consumidores de MDMA, dentre de 20 ó 30 años cuando tengan 45, empezarán a manifestar los síntomas y signos de degeneración del sistema nervioso central que habitualmente no empiezan a observarse hasta los 70 u 80 años."

\subsection{METANFETAMINA}

Es un análogo de la anfetamina (d-N-metilanfetamina) con elevado potencial de abuso. Recibe los nombres callejeros de "speed", "crank", "meth" y otros. Sus efectos estimulantes son análogos a los producidos por la Dextroanfetamina, aunque su paso a sistema nervioso central (SNC) a través de la barrera hemato-encefálica es más rápido por su mayor solubilidad, siendo también su duración de acción más prolongada (6-24 horas). Sus efectos incluyen: insomnio, anorexia, disminución de la sensación de fatiga, aumento de la capacidad de atención, de la sobrestima, euforia, etc..., estimulación central, convulsiones y síntomas cardiovasculares (taquicardia, hipertensión arterial, arritmias, hemorragias cerebrales, estados psicóticos, etc.). Los mecanismos de acción de la metanfetamina incluyen: acciones simpaticomiméticas indirectas y alteraciones de vías dopaminérgicas y serotonérgicas, y sus sistemas enzimáticos como causa de su neurotoxicidad.

Una variante fumada, de la metanfetamina ("ice") ("crystal"), por su gran liposolubilidad, se difunde a cerebro con extraordinaria rapidez, ocasionando sensaciones de euforia e intensa energía, instauración de una rápida dependencia psicológica, con cuadros alucinatorios y estados paranoides. Inyectada por vía endovenosa, produce efectos de tipo cocaína. En algunos individuos se han observado espectaculares pérdidas de peso. 
Debido a la elaboración clandestina de esta sustancia, puede manifestarse una toxicidad añadida originada por los productos intermedios utilizados en los procesos de síntesis, como el ácido fenilacético o el acetato de plomo. En el caso de de éste último compuesto se puede presentar un cuadro de saturnismo (dolor abdominal, anemia, convulsiones, encefalopatía, mialgias, neuropatía motora, hepatitis tóxica e insuficiencia renal).

\subsection{TMA-2 (2,4,5-TRIMETOXIANFETAMI- NA)}

Es una feniletilamina análoga a la mescalina; comparte con otras feniletil-aminas las acciones simpaticomiméticas cardiovasculares (hipertensión, taquicardia, arritmias, etc.) y las acciones estimulantes del SNC; en animales (ratones) aumenta la actividad locomotora y estimula la liberación de catecolaminas y de corticoides de la médula y de la corteza adrenal respectivamente; puede crear drogodependencia de tipo alucinógeno, con manifestaciones alucinatorias visuales, auditivas y cinéticas, acompañadas de estados de euforia, seguidos de estados de ansiedad y angustia.

Su principal riesgo de abuso es su estrecho margen entre dosis euforizante y dosis desencadenantes de angustia y estados psicóticos. Fue incluída en la Lista I del Convenio sobre Sustancias Psicotropas de 1971 en 1986.

Un análogo de TMA, es la PMA (parametoxianfetamina). Produce una intensa estimulación del Sistema Nervioso Simpático y tiene acciones alucinógenas muy potentes. Estudios de discriminación de drogas parecen demostrar que posee efectos análogos a los producidos por LSD, y mediados por vías serotonérgicas.

Su consumo data del inicio de los años 1970, habiéndose descrito muchas intoxicaciones mortales.

\subsection{DOM (4-METIL-2,5-DIMETOXIANFETA- MINA).}

Sintetizada por Shulgin en 1963, fue la primera de estas sutancias que apareció en el mercado ilícito. Relacionado también estructuralmente con anfetamina y mescalina, es el principio activo del preparado STP (Serenity, Tranquility, Peace), que también puede contener sustancias anticolinérgicas (Ditrán) y estuvo muy relacionado con la contracultura Hippie.

Con dosis bajas (2-3 mg) produce estimulación simpática (midriasis, temblor, exaltación de reflejos, taquicardia, hipertensión, etc.); dosis medias (5-8 mg) ocasionan alteración de las percepciones, alucinaciones e intensa estimulación del SNC. Tiene efectos ambivalentes, pues produce euforia y disforia y ausencia del control de las emociones. Dosis más elevadas (10-20 mg) pueden producir intensos efectos psicotrópicos, lo que aumentó su impopularidad e hizo que su consumo decayera pronto. Estudios de discriminación de drogas demostraron que el DOM, es el derivado de feniletilamina con mayores propiedades alucinógenas. Produce igualmente importantes efectos de tipo simpaticomimético en aparato cardiovascular. Sus efectos psicotomiméticos parecen estar mediados por estímulo de receptores de 5HT (5HT2). Fue incluída en la Lista I del Convenio de Sustancias Psicotropas en 1977.

Análogo estructural al DOM y con parecidas acciones farmacológicas es el DOET (2-5dimetoxi-4-etil-anfetamina).

\subsection{DOB (4-BROMO-2,5-DIMETOXIANFE- TAMINA}

Es uno de los compuestos más potentes de la serie estructuralmente relacionado con anfetaminas y mescalina, y tiene una potencia farmacológica 100 veces superior a ésta.

Con dosis de 2-3 mg se inician los efectos en 1 hora, aunque el cuadro completo de intoxicación no se desarrolla hasta las 3 ó 4 horas, y se caracteriza, aparte de los síntomas de una intensa estimulación simpática, 
por un aumento de lucidez del pensamiento, fantasías y distorsiones de percepción sensorial. Al cabo de unas 8-10 horas, empiezan a desaparecer estos efectos.

Sin embargo, se han descrito después de la ingestión de DOB, y debido precisamente a la intensa estimulación simpática, estados de vasoespasmo difuso, que sólo remite con la administración de alfa-bloqueantes simpáticos (tolazolina) por vía intraarterial o de nitroprusiato sódico por vía endovenosa. Las consecuencias de la intensa estimulación simpática, que produce esta droga, en aparato cardiovascular y sistema nervioso central puede ocasionar la muerte. Está incluida en la lista I del Convenio de Sustancias Psicotropas en 1985.

\subsection{C-B (4-bromo-2,5-dimetoxifenil-anfe- tamina)}

Es un análogo estructural del DOB, conocido en la nomenclatura callejera como "after turner" "toonies" y "nexus". Es 10 veces menos potente que el anterior y a dosis bajas se ha descrito un efecto como de "relajación" del pensamiento, causando dosis elevadas cuadros de alucinaciones y estados de agitación. En un principio el uso de esta droga estaba limitado a un pequeño grupo de la población de Texas donde fue detectado por la DEA en 1979. Posteriormente, a partir de 1986, aparecieron laboratorios clandestinos de 2C-B en muchos estados de EE.UU. Fue incluída en la Lista I en 1995.

La forma habitual de presentación de la 2C-B es en cápsulas para administración oral y ocasionalmente en forma de sal hidroclorada que permite su administración por vía nasal.

\subsection{MDA (3-4-METILENDIOXIANFETAMI- NA)}

Sintetizada en 1910, fue estudiada farmacológicamente en 1939 con algunos intentos de introducirla en terapéutica para suprimir el apetito y también como antitusígena y antidepresiva, intentos que no fructificaron. Fue incluída en la Lista I en 1985. Conocida como "píldora del amor" (love drug) y perteneciente también a las llamadas, quizás impropiamente, anfetaminas alucinógenas, fué en su momento una de las drogas más consumidas. Dosis bajas (30-40 mg) producen una "leve" intoxicación con sensación de empatía y de euforia, sin ocasionar estados alucinatorios. Sin embargo, con dosis más elevadas se han descrito casos de intensa estimulación del SNC, con cuadros de agitación, delirio y alucinaciones, acompañadas de convulsiones, hipertermia, crisis hipertensivas, taquicardia, coagulación intravascular diseminada, rabdomiolisis y parada cardíaca. Sus efectos psicomiméticos son análogos a los producidos por LSD y anfetaminas. La MDA es, a su vez, uno de los metabolitos de la MDMA, y responsable parcial de la neurotoxicidad de ésta.

Es importante señalar que en los procesos de elaboración clandestina de este compuesto se utilizan algunos precursores, como la metilendioxi-bencilacetona que puede derivar a la síntesis de un análogo de MDA, el HMDA, de toxicidad superior a MDA.

Las investigaciones sobre los mecanismos de la toxicidad de MDA, han estado muy ligados a las de MDMA; ambas son sustancias que producen neurotoxicidad serotonérgica. Pero estudios experimentales de discriminación efectuados en diversas especies animales han demostrado la existencia de diferencias específicas entre MDA y MDMA. En animales entrenados para discriminar entre efectos estimulantes y efectos alucinógenos, la MDMA se comporta más como una sustancia de tipo anfetamínico, mientras que la MDA se comporta más como una sustancia de tipo alucinógeno.

\subsection{MDEA (MDE) (N-ETIL-3,4-METILEN- DIOXIANFETAMINA).}

Conocida en la denominación callejera con el nombre de "EVA" es químicamente un 
congénere N-etilado de la MDMA. Tiene cierta popularidad como droga recreativa, aunque según encuestas realizadas entre sus consumidores, parecen preferir la MDMA. Las investigaciones acerca de su farmacología y toxicología han ido muy paralelas a las llevadas a cabo sobre MDMA y MDA.

Según investigaciones de discriminación de drogas la MDEA tiene efectos farmacológicos semejantes a los producidos por MDMA.

Así, en experimentación animal, disminuye la actividad triptófano-hidroxilasa (TPH), y las concentraciones de $5 \mathrm{HT}$ y $5 \mathrm{HIAA}$ en varias áreas cerebrales (corteza frontal, hipocampo y neoestriado), no modificándose la actividad tiroxina hidroxilasa.

Su actividad depletora de 5HT parece ser, sin embargo, menos potente que la de MDA y MDMA; y la capacidad de recuperación de la actividad TPH, expresada por la concentración de 5HT y 5HIAA, después de múltiples dosis de MDEA fue más rápida que la observada después de MDA ó MDMA.

En general, la neurotoxicidad serotonérgica es menor $y$ de efecto menos duradero que el de MDA y MDMA.

Se han registrado, sin embargo, numerosos casos de toxicidad aguda, y algunos casos mortales entre sus consumidores. Fue incluída en la Lista I en 1990. No obstante, en los años 1990 y 1991 investigadores psiquiátras alemanes la utilizaron en algunos ensayos, llegando a la conclusión de que la MDEA podría considerarse como entactógena. Fue prohibida en 1992 y suspendida toda investigación clínica.

\subsection{OTRAS FENILETILAMINAS.}

En el año 1986 en Toronto (Canadá), se detectó la fabricación clandestina de los siguientes derivados anfetamínicos:

- 4-Etoxi-2,5-dimetoxianfetamina (MEM)

- Metoxi-4,5-metilendioxianfetamina (2MMDA)
- N,N-dimetil-3,4-metilendioxianfetamina (N,N-dimetil-MDA)

- N-etil-3,4-metilendioxianfetamina (MDE).

Una sustancia sintetizada en 1986, y considerada como prototipo de sustancia enctactógena, es la MBDB (N-metil-1-(3,4-metilendioxifenil)-2-butanamina. Tiene acciones análogas a la MDMA. Recientemente, ha hecho aparición en el mercado clandestino un nuevo derivado anfetamínico, la N-hidroxi-3,4 metilendioximetanfetamina ( $\mathrm{N}-\mathrm{OH}-\mathrm{MDMA}$ ), cuya sal de oxalato ha sido denominada FLEA.

Parece haberse detectado una síntesis clandestina a gran escala de esta sustancia en varios laboratorios europeos, lo que sugiere que esta droga puede ser una de las últimas drogas de diseño.

El control federal en EE.UU. de los precursores químicos utilizados en la síntesis de MDMA y MDA ha desviado la fabricación de estos compuestos a otros análogos estructurales tales como 1-(3,4 dimetoxifenil)-2-propranamina (3,4-dimetoxianfetamina y sus derivados $\mathrm{N}$-metil-N-etil y N,N-dimetil de características fármaco-toxicológicas semejantes.

\section{OPIOIDES SINTÉTICOS.}

Desde finales de los años 1970s la restricción legal y el control policial del consumo de heroína hizo que varios laboratorios clandestinos sintetizaran nuevos opiáceos que fueron denominados "heroínas sintéticas" o heroínas artificiales. Dentro del grupo de compuestos opiáceos tienen interés como drogas de diseño: los derivados del fentanilo, y derivados de la meperidina.

\subsection{Derivados del Fentanilo.}

El fentanilo, 80 a 100 veces más potente que la morfina como analgésico, se utiliza fundamentalmente en las modernas técnicas 
de anestesia con opiáceos en cirugía cardiovascular y las UCls.

La irrupción del fentanilo en el mercado ilícito comenzó en los años 1980s en California (EE.UU.), registrándose entre los consumidores frecuentes muertes repentinas que se atribuyeron en un principio a una posible partida de heroína en estado muy puro, y a la que se le dió el nombre de "China white".

Investigaciones posteriores revelaron que la causa de esas muertes era un compuesto opiáceo, derivado del fentanilo, el alfametilfentanilo (AMF), elaborado clandestinamente por un laboratorio no identificado (Information Manual of Designer Drugs). El compuesto no sólo era más potente que la heroína como analgésico, sino que era íntensamente dependígeno, además de contener impurezas que le conferían una toxicidad añadida. Resultó ser una sustancia liposoluble por lo que atravesaba muy fácilmente la barrera hematoencefálica, penetrando rápidamente en el sistema nervioso central (SNC). La muerte era producida generalmente por una intensa y rápida depresión respiratoria.

La asociación de alfametilfentanilo con heroína, denominada "Tango y Cash", resultó también muy tóxica, habiéndose registrado una alta mortalidad entre los consumidores.

A este primer derivado del fentanilo le siguieron una serie de análogos con toxicidad variable.

Uno de ellos, el 3-metilfentanilo (3-MF), 15-20 veces más potente que el fentanilo, y 100 veces más potente que la heroína y de alta toxicidad.

Otros análogos del fentanilo, eventualmente utilizados por los consumidores de drogas y altamente tóxicos, son el parafluorofentanilo (PFF) y el alfametil-acetilfentanilo (AMAF) (Fig. 3).

\subsection{Derivados de la meperidina (Petidina).}

La meperidina descubierta inicialmente como agente anticolinérgico-espasmolítico, es un potente analgésico (10 veces menos que la morfina), con capacidad adictógena.
La síntesis clandestina de un derivado de la meperidina, el MPP (1-metil-4-fenil-propionoxipiperidina), dió lugar en uno de los procesos de la síntesis a la obtención de un producto intermedio contaminante, el MPTP (1-metil-4 fenil-1,2,3,6 tetrahidropiridina) que fué autoadministrado por muchos heorinómanos en sustitución de la heroína, en el estado de California en los años 1980s (Fig. 3).

La administración parenteral de MPP, contaminado con MPTP, produjo un cuadro de disforia, alucinaciones visuales y auditivas y dolor y quemazón local en el sitio de la inyección, pero tras varios días de repetidas administraciones, se producía un cuadro de parkinsonismo con acinesia, catatonia, rigidez, cara de máscara, hipofonía y temblor. En muchos casos se originaron parálisis e invalidez irreversibles, habiéndose registrado casos de suicidio.

Este parkinsonismo no es idéntico al observado en la Enfermedad de Parkinson idiopática ya que no se observó el mismo grado de demencia ni las mismas alteraciones estructurales (cuerpos de Levy), si bien en ambos procesos ocurre una destrucción de neuronas dopaminérgicas en la sustancia nigra y suelen responder a la terapéutica convencional antiparkinsoniana.

La MPTP se ha convertido en una sustancia útil en la investigación de los mecanismos patogénicos selectivos de la Enfermedad de Parkinson ya que tras la administración de este compuesto y por la acción de la MAO B cerebral, que se encuentra en las neuronas dopaminérgicas, se produce MPP+ (1-metil, 4-fenilpiridinio) compuesto que destruye selectivamente la zona compacta de la sustancia nigra, sin afectar a las neuronas dopaminérgicas de otros núcleos.

\section{ARILHEXILAMINAS.}

El representante más conocido y típico de esta familia química es la Fenciclidina (PCP, "polvo de angel", "píldora de la paz") (Fig. 3). Fue introducida inicialmente en medicina 
Figura 3. Drogas de diseño. Opiáceos derivados de fentanilo y de meperidina) y arihexilaminas [fenciclidina (PCP)]

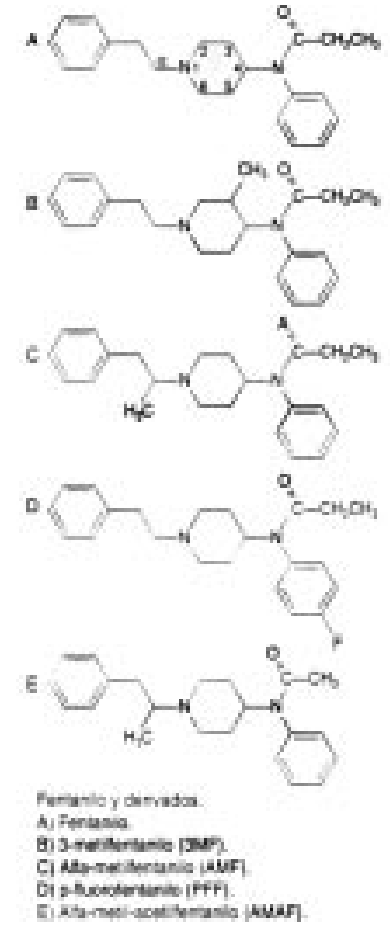

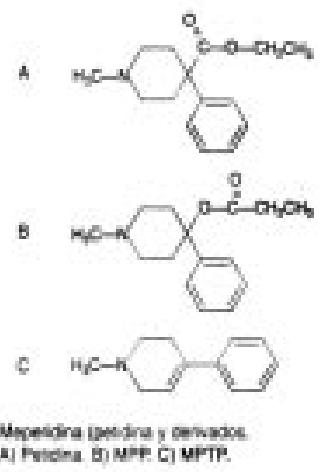

w) Feidina Bi Mor Ci VPTP.

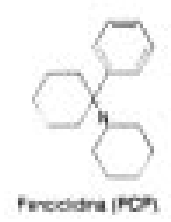

como anestésico general; administrado por vía endovenosa produce una analgesia-anestesia sin pérdida completa de la conciencia. A mediados de los años 1960s fué prohibido su uso en medicina humana, manteniéndose su uso en medicina veterinaria como anestésico.

Los efectos somáticos y psicológicos de la fenciclidina son dosis-dependientes. Dosis bajas originan euforia y sensación de despersonalización, además de estimulación simpática (taquicardia, hipertensión, midriasis, etc.), nistagmo y modificaciones en la percepción del dolor (por efecto analgésico). Dosis más elevadas producen cuadros de agitación, con comportamiento violento ocasionalmente, estados alucinatorios y paranoides. Los animales de experimentación se autoadministran PCP en los tests psicofarmacológicos de autoadministración de drogas, lo que demuestra el efecto reforzador positivo de esta sustancia.

La hiperestimulación simpática, además de taquicardia e hipertensión, puede producir hipertermia e hiperreflexia. Casos más graves pueden manifestarse por rabdomiolisis, acidosis, convulsiones y parada respiratoria.

El tratamiento de esta intoxicación requiere medidas urgentes: diuresis forzada alcalina, carbón activo en dosis repetidas para impedir la circulación enterohepática que sufre este compuesto, benzodiazepinas o neurolépticos.

La síntesis química de los derivados de arilhexilaminas resulta relativamente sencilla. Derivados de la fenciclidina son el PCC (piperidinociclohexanocarbonitrilo), TPC (análogo 
tiofeno de la PCP) y PCE (análogo N-etil de la PCP) y PHP (fenilcihexil-pirrolidina). Sus acciones son análogas a las de la PCP.

Un derivado de fenciclidina, utilizado en terapéutica es la Ketamina con acciones farmacológicas parecidas aunque menos intensas.

Se utiliza en medicina humana como anestésico de acción breve. Se administra por vía endovenosa o intramuscular; produce anestesia disociativa en la que el paciente puede permanecer consciente aunque amnésico e insensible al dolor.

Después de una sola dosis, la pérdida del conocimiento dura 10 a 15 minutos y la analgesia persiste durante 40-50 minutos; la amnesia puede mantenerse durante 1 ó 2 horas después de la inyección inicial; a veces, durante el periodo de analgesia-amnesia se observan reacciones violentas e irracionales a los estímulos. La recuperación de una anestesia con Ketamina tiene unas características peculiares; el despertar total puede requerir varias horas con manifestación de sensaciones psíquicas intensas, experiencias disociativas de la propia imagen, estados ilusorios, náuseas, vómitos, alucinaciones, confusión y conducta irracional, habiéndose descrito por los pacientes sueños desagradables y, en ocasiones, sueños placenteros con fantasías eróticas. A veces, estas sensaciones reaparecen días o semanas después. Casi el $50 \%$ de los adultos mayores de 30 años experimentan estos efectos colaterales.

La incidencia de estas experiencias psicológicas adversas es mucho menor en niños y se puede reducir con la administración previa de un tranquilizante de tipo benzodiacepínico: midalozam.

Administrada asociada al diacepam (Valium) produce una anestesia satisfactoria, estando particularmente indicada como anestésico en niños para intervenciones quirúrgicas menores o curas dolorosas de quemaduras, manipulaciones ortopédicas, etc.. También está indicada en intervenciones obstétricas y ginecológicas.
Ultimamente se ha ensayado con resultados satisfactorios en la anestesia epidural durante el parto.

Igual que la PCP, se utiliza principalmente en medicina veterinaria como anestésico.

Como droga de abuso, la Ketamina ha sido utilizada en EE.UU. y Canadá.

Las preparaciones callejeras se hacían con polvo, cápsulas, tabletas y soluciones líquidas; también en inyectables (dosis de $50 \mathrm{mg}$ ) o esnifada (60 a $100 \mathrm{mg}$ ); a estas dosis se mantiene generalmente la conciencia. Es conocida en la jerga de los drogadictos como "Special Kó Vitamina K".

Los efectos buscados por los consumidores son euforia y "revelaciones místicas," así como alucinaciones y sensaciones placenteras (sensación de flotar o sensación de estímulo). Los consumidores de Ketamina experimentan, generalmente, deterioro de los procesos cognitivos, vértigos, incoordinación motora, lenguaje incoherente y confusión. Muchas veces ocurren reacciones adversas graves (mal viaje) que semejan los estados psicóticos producidos por la fenciclidina (PCP). Son frecuentes los "flashbacks" (recurrencia de experiencias psíquicas vividas en la época en que se consumió la droga). Este fenómeno ha sido descrito también en pacientes que utilizaron la Ketamina con fines médicos.

En la actualidad la Ketamina no es muy aceptada como droga de abuso en el ámbito de la drogodependencia. Pertenece al grupo de las denominadas "date rape drugs" (ver ghidroxi-butirato).

\section{DERIVADOS DE METACUOLONA.}

La metacualona es una quinazolina con propiedades sedantes, hipnóticas y anticonvulsivantes, espasmolíticas, antitusígenas y antihistamínicas. Ha sido retirada del uso médico en muchos países. Se mantiene su uso legal en España. En EE.UU. se conoce con los nombres callejeros de "Sopes" y 
"Ludes" denominación tomada de los entonces nombres registrados Sopor $\AA^{\circ}$ y Qualude $\circledast$. Algunos derivados, de síntesis clandestina, son la meclocualona y la nitrometacualona (10 veces más sedante que la metacualona).

Estos compuestos producen a determinadas dosis un estado de desinhibición, euforia y estimulación psíquica. Por su fama de aumentar la líbido se la conoció como "droga del amor". Desarrollan tolerancia con el uso contínuo y producen dependencia física y psicológica análoga a la producida por los barbitúricos. Dosis más elevadas provocan ataxia y letargia, edema pulmonar y cutáneo, hipotensión y arritmias. La sobredosis puede ocasionar contracturas musculares y coma.

\section{OTROS.}

Metcatinona, conocida también como efedrona, 2-metilamino-1-fenilpropanona hizo su aparición en los últimos años en EE.UU., como estimulante del SNC y utilizada en algunos países como potente supresor del apetito. En 1992 fué detectado su fabricación en laboratorios clandestinos de EE.UU. y Rusia a partir de la efedrina.

Sus efectos farmacológicos son análogos a los producidos por anfetaminas. Su potencia farmacológica es 1,5 veces superior a la de la metanfetamina.

El Aminorex y el 4-metilaminorex, cuyo nombre callejero es U-4-E-Uh, son derivados de oxazolina, estimulantes del SNC con elevado potencial de abuso y efectos análogos a los de las anfetaminas.

En principio fueron sintetizados como supresores del apetito (1965) y como tales fueron introducidos en la práctica médica.

Posteriormente fueron retirados por su toxicidad (estimulación simpática e hipertensión pulmonar).

Gamma-Hidroxibutirato (GHB, gOH, Oxibato sódico). Denominado indebidamente en el argot de los consumidores "Extasis líquido", es un derivado hidroxilado del GABA y fué sintetizado por Laborit en 1967; atraviesa muy bien la barrera hematoencefálica y es un potente depresor del SNC. Fué introducido en medicina como anestésico, siendo utilizado en anestesia obstétrica (facilita la dilatación del cuello del útero) en narcolepsia, y en el tratamiento de la adicción al alcohol y la heroína. Estimula la secreción de la hormona del crecimiento, por lo que fue consumido eventualmente por los culturistas. Al principio de los años 1990s la FDA de EE.UU. lo retiró del mercado "por seguridad pública", habiéndose informado de varios casos de intoxicación, considerándose esta sustancia como de "gran potencial de abuso".

Los pacientes entrevistados, consumidores de GHB, manifestaban experimentar una agradable excitación; en algunos casos, se produjeron alucinaciones, delirio, estados de intensa euforia y efectos anestésicos; en otros, los primeros síntomas fueron somnolencia, hipotonía muscular, cefaleas y estados de confusión; los casos más graves pueden evolucionar hacia el coma, con grave depresión respiratoria y muerte. Sus efectos aparecen al cabo de 5 ó 10 minutos de ser ingerido y duran aproximadamente de 1 hora y media a 3 horas.

En general, sus efectos son impredecibles y varían mucho de unas personas a otras. Algunos los comparan al efecto del alcohol, potenciándose el efecto de ambas drogas cuando se consumen simultáneamente.

El GHB se presenta como un líquido incoloro, inodoro e insípido o ligeramente salado, pudiendo mezclarse con agua u otra bebida, quedando enmascarado su presencia, por lo que es más difícil de controlar su consumo, aumentando el peligro de intoxicación. En España fue detectado su tráfico y consumo en 1995.

Junto con el flunitracepam (Rohipnol) y la Ketamina pertenece a las llamadas "date rape drugs" (drogas de violación por cita); que mezcladas con alcohol pueden incapacitar a las posibles víctimas de una violación, para resistir el ataque sexual. 
La legislación federal de EE.UU. ha incrementado las penas por el uso de sustancias que contribuyan a la violencia sexual.

La gammabutirolactona (GBL) y el butanediol (BD) precursores del gammahidroxibutirato y con sus mismas acciones farmacológicas son también consumidos por los culturistas. Producen una marcada dependencia y un síndrome de abstinencia a las pocas horas de suspender su administración, caracterizado por ansiedad, insomnio, ilusiones paranoides, temblores, taquicardia e hipertensión arterial. Esta sintomatología es muy intensa durante las primeras horas atenuándose paulatinamente hasta su desaparición a los 14 días.

El tratamiento debe llevarse a cabo con la administración de fármacos barbitúricos; las benzodiacepinas no parecen ser eficaces.

\section{Extasis Vegetal.}

La tendencia a practicar la fitoterapia como alternativa a la terapéutica farmacológica convencional por creer, erróneamente que las sustancias "naturales" derivadas de las plantas son innocuas frente a las sustancias "químicas", se ha trasladado también al mundo de las drogodependencias.

Así existe una tendencia a consumir "drogas naturales" frente a las "drogas químicas", en la creencia de que aquellas carecen de los efectos adversos de éstas.

Entre las llamadas "drogas naturales" han surgido con fuerza las agrupadas bajo el nombre de Extasis Vegetal, considerándolo, erróneamente, una alternativa "sana y segura" al éxtasis químico (MDMA).

El Extasis Vegetal es una compleja mezcla no estandarizada de plantas y productos químicos, siendo los más conocidos:

1) Plantas con bases xánticas: nuez de cola, guaraná, té, ricos en cafeína.

2) Plantas con precursores anfetamínicos: Efedra (mahuang) rica en efedrina y pseudoefedrina, bala, con efedrina, Calamo aromático, rico en asarona, aceite esencial rico en trimetilanfeta-mina.
3) Plantas cuyo uso requiere control médico: Passiflora, con alcaloides indólicos (harmalina, harmina, etc.) con variados efectos farmacológicos (hipnóticos, anticonvulsivantes, inhibidores de MAO, etc.), Ginkgo biloba rico en biflavonoides y diterpenos, con acciones vasodilatadoras, Ginseng, con saponinas triterpénicas (gingenósidos) con múltiples acciones farmacológicas.

4) Plantas ajenas a la tradición fitoterapéutica española: Kava-Kava, contiene sustancias terpénicas (kavapironas) con actividad hipnosedante, Salvia de los Adivinos, cuyas hojas contienen sustancias alucinógenas, Yohimbe rica en yohimbina, con importantes acciones farmacológicas cardiovasculares.

5) Otras sustancias: L-arginina, fenilalanina, GABA, etc.

Es decir, el llamado Extasis Vegetal contiene innumerables sustancias con muy variadas acciones farmacológicas, no exentas de importantes efectos secundarios.

Sus efectos más importantes son el efecto estimulante de la corteza cerebral debido a la cafeína y otras xantinas, y un efecto análogo al de las anfetaminas debido a la efedrina, asarona y otros análogos estructurales de las anfetaminas.

A pesar de la pretendida seguridad de estas plantas medicinales, todas estas especies presentan efectos secundarios, interacciones farmacológicas y contraindicaciones difíciles de controlar pues al no estar su fórmula estandarizada, dependerán de las especies vegetales presentes en su composición.

El Extasis Vegetal por sus acciones simpaticomiméticas, estará contraindicado en personas que padezcan: trastornos cardiovasculares (hipertensión, insuficiencia cardíaca, cardiopatía isquémica), hipertiroidismo, diabetes (la efedrina eleva la glucemia y el Ginseng la desciende alterando su regulación), ansiedad, glaucoma, así como en estados depresivos (el Kava-Kava es depresor del SNC y en embarazo y lactancia (se eliminan parcialmente por la leche y pueden intoxicar al feto).

Asimismo, los componentes del Extasis Vegetal presentan interacciones con los si- 
guientes medicamentos: Digitálicos (xantinas y efedrina potencian sus efectos), IMAO (Passiflora y xantinas y efedrina potencian sus efectos), Depresores del SNC: Alcohol, benzodiacepinas o barbitúricos (Kava-Kava y Passiflora potencian sus efectos), Anticoagulantes orales y antiagregantes plaquetarios (Ginseng y Ginkgo potencia sus efectos pudiendo desencadenar hemorragias), Heparina (su asociación con Ginkgo aumenta la frecuencia de hemorragias cerebrales).

Tampoco se deben asociar con antidiabéticos, corticoides y estrógenos.

Las principales reacciones adversas a que da lugar el consumo de estas sustancias son: insomnio, estados de excitabilidad y nerviosismo, cefaleas, naúseas, vómitos, dolor abdominal, gastritis, taquicardia, hipertensión y reacciones alérgicas de distinto tipo.

No hay que olvidar que los componentes del Extasis Vegetal son plantas medicinales y están sometidas a controles legales y según la Ley 25/1990 del Medicamento (20 Diciembre), "Las plantas medicinales deberán ser dispensadas sólo en Oficinas de Farmacia y bajo la supervisión profesional del farmacéutico".

El Extasis Vegetal debe ser considerado una droga de abuso según los criterios de la OMS, y su fabricación, distribución y venta está prohibida; los laboratorios que los fabrican y distribuyen carecen de autorización de comercialización (la información y venta a través de Internet debiera ser controlada); en su fabricación no existe control de calidad y los lugares de venta carecen de las medidas de seguridad adecuadas, con el agravante de que la ausencia de información objetiva lleva a la errónea creencia de que por ser los componentes del Extasis Vegetal, plantas naturales, son inofensivos y carentes de efectos secundarios.

\section{ALUCINÓGENOS.}

\subsection{Definición y clasificación.}

En este apartado se incluye a un grupo heterogéneo de sustancias capaces de provocar alteraciones sensoriales. Para denominarlas, en farmacología se utilizan indistintamente los términos de alucinógeno, psicomimético, psicodislépticos o psicodélicos. Se define alucinación como la percepción sensorial sin fundamento en el mundo exterior; ilusión en cambio es la interpretación falsa de una imagen sensitiva real.

Los alucinógenos son sustancias, naturales o sintéticas, que tradicionalmente han formado parte de rituales religiosos y ceremonias mágicas en numerosas culturas. Los datos epidemiológicos son tratados en el capítulo 4 de esta monografía. En general, se acepta que no producen dependencia, pero su uso se asocia al consumo de otras sustancias capaces de producir dependencia. El estudio de su farmacología no es sencillo ya que, generalmente, se trata de extractos obtenidos de plantas, con múltiples principios farmacológicos con acciones distintas entre sí (Tabla II).

No existe una clasificación clara de los alucinógenos ya que muchas sustancias o fármacos con acciones a nivel central pueden provocar efectos psicomiméticos. Los alucinógenos se pueden clasificar en función de su estructura química (Tabla III) y de su similitud con determinados neurotransmisores del SNC en:

\section{a) Indolalquilaminas y otros derivados indólicos.}

- Grupo relacionado con el ácido lisérgico. El producto alucinógeno prototípico y mejor estudiado es la lisergida, dietilamida del ácido lisérgico, LSD-25 o simplemente LSD; descubierto por Hoffman en 1943. Es el compuesto de referencia para el estudio de los efectos farmacológicos de los alucinógenos. 
Tabla II. Clasificación de los alucinógenos

INDOLALOUILAMINASY OTROS DERIVADOS INDÓLICOS

LSD (lisergida, dietilamida del ácido lisérgico o LSD-25)

Psilocibina y psilocina

DMT o dimetil triptamina y DET o dietiltriptamina (sintético)

Ibogaína

Alcaloides de la harmala: Harmina, harmalina, harmalol

Bufotenina o N-dimetilserotonina.

SUSTANCIAS RELACIONADAS ESTRUCTURALMENTE CON LAS FENILETILAMINAS.

Mescalina

Elemicina y miristicina

Metoxianfetaminas

\section{ANTICOLINÉRGICOSY COLINÉRGICOS}

Atropina

Escopolamina

Muscarina, ácido iboténico y el muscimol.

\section{ARILHEXILAMINAS (ARILCICLOALQUILAMINAS)}

Fenciclidina

Ketamina

\section{OTROS}

Derivados de la Cannabis Sativa

Opiáceos

\begin{tabular}{|c|c|c|c|c|}
\hline \multicolumn{5}{|c|}{ Tabla III. Características principales de algunos alucinógenos } \\
\hline Droga & Fuente Biológica & Vía de administración & Dosis habitual & Duración efectos \\
\hline \multicolumn{5}{|l|}{ INDOLALQUILAMINAS } \\
\hline $\begin{array}{l}\text { LSD } \\
\text { Psilocibina } \\
\text { DMT (dimetil triptamina) } \\
\text { lbogaína } \\
\text { Harmina } \\
\text { Bufotenina }\end{array}$ & $\begin{array}{l}\text { Hongos en centeno, semisintética } \\
\text { Psilocybe, Stropharia y Paneolus } \\
\text { Mimosa, Virola y Piptadenia } \\
\text { Tabeernanthe iboga } \\
\text { Banisteriopsis caapi } \\
\text { Bufo vulgaris / Piptadenia peregrina }\end{array}$ & $\begin{array}{l}\text { Oral } \\
\text { Oral } \\
\text { Intranasal/ Parenteral/ NO oral } \\
\text { Oral (raices en polvo) } \\
\text { Oral (en infusiones) } \\
\text { Pulmonar/Intranasa// NO oral }\end{array}$ & $\begin{array}{l}100 \mu \mathrm{g} \\
4-6 \mathrm{mg}(5-10 \mathrm{~g} \text { polvo seco) } \\
50-100 \mathrm{mg} \\
200-400 \mathrm{mg} \\
300-400 \mathrm{mg} \\
1-20 \mathrm{mg}\end{array}$ & $\begin{array}{l}\text { 6-12 horas } \\
4-6 \text { horas } \\
30-60 \text { minutos } \\
8-12 \text { horas } \\
4-8 \text { horas }\end{array}$ \\
\hline \multicolumn{5}{|l|}{ FENILETILAMINAS } \\
\hline $\begin{array}{l}\text { Mescalina } \\
\text { Elemicina, miristicina }\end{array}$ & $\begin{array}{l}\text { Cactus Peyote (I. Williamsii) } \\
\text { Nuez Moscada (Myristica fragrans) }\end{array}$ & $\begin{array}{l}\text { Oral } \\
\text { Oral } \\
\end{array}$ & $\begin{array}{l}200-400 \mathrm{mg} \text { (4-6 g de cactus) } \\
10-30 \mathrm{~g} \text { de nuez moscada }\end{array}$ & $\begin{array}{l}10-12 \text { horas } \\
6-12 \text { horas }\end{array}$ \\
\hline \multicolumn{5}{|l|}{ ANTICOLINÉRGICOS/COLIN. } \\
\hline $\begin{array}{l}\text { Atropina } \\
\text { Escopolamina } \\
\text { Ácido iboténico y muscimol }\end{array}$ & $\begin{array}{l}\text { Atropa Belladona, Datura stramonium } \\
\text { Hyoscyamus niger, Scopolia carniolica } \\
\text { Amanita Muscaria }\end{array}$ & $\begin{array}{l}\text { Oral } \\
\text { Oral } \\
\text { Oral }\end{array}$ & \multicolumn{2}{|c|}{$>10 \mathrm{mg}$ alucinaciones, delirio y coma } \\
\hline
\end{tabular}

- Psilocibina y la psilocina, principios activos de diversos hongos (del género Psylocibe, Stropharia y Paneolus)

- La DMT o dimetil triptamina es producida por plantas como Mimosa, Virola y Piptadenia, pero también puede ser obtenida sintéticamente, lo mismo que la DET o dietiltriptamina.

- Otros derivados triptaminérgicos de interés son la ibogaína, alcaloide de las raíces y granos de la especie africana Tabeernanthe iboga. 
- Los alcaloides de la harmala: harmina, harmalina, harmalol, que son algunos de los principios activos de las bebidas alucinógenas sudamericanas Ilamadas Ayahuasca (o Caapi o Yagé). Se preparan con especies de la liana selvática Banisteria; también es rica en estos alcaloides la Peganum harmala, planta originaria de África y de las estepas rusas, sirias e indias.

- La bufotenina (5-hidroxi-N,N-dimetiltriptamina) o $\mathbf{N}$-dimetilserotonina es una alquilhidroxi-triptamina que se aisla de las glándulas cutáneas del sapo (Bufo vulgaris) y de la planta mimosácea Piptadenia peregrina y algunos análogos que se encuentran en las semillas de determinadas leguminosas sudamericanas.

\section{b) Sustancias relacionadas estructural- mente con las feniletilaminas.}

- La mescalina es el alcaloide principal del cactus peyote y presenta unos efectos comparables a los de la LSD, en los que predominan las acciones simpaticomiméticas.

- La elemicina y la miristicina se encuentran en la nuez moscada: sólo poseen propiedades psicomiméticas a dosis muy elevadas.

- Las metoxianfetaminas son variantes anfetamínicas con propiedades alucinógenas cuyo estudio ya ha sido comentado previamente.

\section{C) Anticolinérgicos y colinérgicos.}

- La atropina y escopolamina se encuentran en plantas como la mandrágora, belladona, estramonio, beleño, etc...

- El ácido iboténico y el muscimol, principios activos con propiedades alucinógenas de la seta Amanita muscaria.

\section{d) Arilhexilaminas (arilcicloalquilaminas)}

- La fenciclidina ya vista previamente.
- La ketamina que es un derivado de la fenciclidina.

e) Otras sustancias que se estudian en otras monografías también producen efectos psicomiméticos. Derivados de Cannabis sativa y los opiáceos también pueden tener efectos alucinógenos. Por último, otros fármacos que pueden presentar efectos alucinógenos como efectos adversos son los corticoides, los esteroides sexuales etc...

\section{2. $L S D$}

El descubrimiento de las propiedades psicodislépticas de la dietilamida del ácido lisérgico fue casual. Hofmann, un investigador de los laboratorios Sandoz, la sintetizó en 1938 junto con otros "ergoderivados" (derivados de alcaloides del cornezuelo del centeno). Por tratarse del número 25 de una serie recibió el nombre de LSD 25 (Lysergsáure Diethylamid 25).

\section{a) Farmacocinética}

Aunque el LSD se absorbe bien por cualquier vía, la habitual es la oral. Se metaboliza por hidroxilación y se conjuga a nivel hepático. Del total ingerido, sólo una pequeña cantidad alcanza el cerebro. Sin embargo, por ser un compuesto muy potente, bastan dosis muy bajas para producir síntomas psicodislépticos. Su semivida es de 1.7 horas. A pesar de ello, sus efectos aparecen al cabo de unos 30-90 min, tienen su máximo unas 3-5 horas después de la ingesta y posteriormente van declinando, pudiendo durar de 8 a 12 horas y hasta varios días. La dosis habitual es de 50-200ug.

\section{b) Mecanismo de acción}

Aunque en sistemas periféricos el LSD se comporta como un antagonista serotonérgico, en el SNC actúa como agonista parcial de los receptores $5-\mathrm{HT}_{2}$, tanto pre como postsinápticos, mimetizando efectos propios de los sistemas serotonérgicos centrales, e inhi- 
biendo la activación de neuronas serotonérgicas de los núcleos del rafe a través del estímulo de autoreceptores. Los subtipos de receptores $5-\mathrm{HT}_{2 \mathrm{~A}}$ y el $5-\mathrm{HT}_{2 \mathrm{C}}$ son los que están implicados en esta acción. La ketanserina bloquea algunos de los efectos específicos del LSD. El LSD activa también receptores dopaminérgicos. Todas estas acciones al parecer ocasionan un desequilibrio funcional a diversos niveles (áreas corticales, sistema límbico, etc.), contribuyendo a distorsionar su acción integradora.

\section{c) Efectos agudos}

EI LSD es una de las sustancias más potentes que se conocen. Cantidades de 50$100 \mu \mathrm{g}$ por vía oral ya causan alteraciones psicodislépticas. La intensidad de los efectos depende de la dosis, pero cuando se utilizan dosis elevadas ya no hay cambios cuantitativos.

Los efectos psíquicos que aparecen en los primeros momentos tras ingerir LSD son una sensación de tensión interior que se alivia llorando o riendo $y$, dependiendo mucho de las expectativas del sujeto, un estado de euforia. Al cabo de dos o tres horas se presenta el cuadro característico de síntomas psicodislépticos que conforman el "viaje" o "trip» psicodélico. EI LSD produce alteraciones en varias funciones psicológicas:

a) En la percepción se afecta sobre todo la esfera de lo visual y en menor medida la concepción subjetiva del tiempo. Inicialmente, la visión se agudiza. Los colores se ven más vivos, aumenta la percepción de la profundidad y los contornos aparecen más nítidos. Las personas y los objetos adquieren un carácter fascinante, los objetos del entorno cobran gran interés, aumenta exageradamente la sensibilidad para los pequeños detalles; más tarde pueden aparecer distorsiones en las formas y en los contornos de los objetos que se visualizan. Se trata de pseudoalucinaciones que el sujeto reconoce como irreales. Las auténticas alucinaciones son menos frecuentes. Los demás sentidos también se afectan en lo que respecta al oído, los ruidos de fondo se oyen con mayor nitidez y aumenta la percepción de la música, incluso en personas normalmente carentes de sentido musical. Puede haber sinestesias, es decir, mezcla de sensaciones o percepción de unas sensaciones transformadas en otras. Los colores se perciben como sonidos o la música como imágenes visuales. Mientras que la sensibilidad dolorosa disminuye, la sensibilidad a la temperatura y a la presión aumenta. De igual modo, se altera la percepción y la imagen corporal. Por ejemplo, la cabeza puede sentirse muy pesada o muy ligera, el pie parece estar situado a varios metros de distancia del ojo. En ocasiones, se difuminan las relaciones entre la persona y su entorno que puede asociarse con accidentes e incluso suicidios. La orientación temporal, finalmente, se pierde. Generalmente, el tiempo se hace más lento, "los minutos pasan lentos como horas", pero a veces, transcurre muy rápido traspasándose los límites del tiempo y mezclándose presente, pasado y futuro.

b) En cuanto al umbral emocional frente a los estímulos externos, por ejemplo, puede aumentar la capacidad de sugestión, de manera que cualquier asunto de carácter ordinario puede percibirse con un simbolismo extraordinario; de ahí la importancia que siempre se ha atribuido a la presencia de un "conductor» experimentado, ya que la labilidad emocional generada por el LSD puede ocasionar que algunos consumidores pasen fácilmente de un estado depresivo a un estado hipomaníaco o desde la alegría a la ansiedad y al miedo.

c) En la organización del pensamiento, es característica la profusión atolondrada de ideas que el individuo se ve incapaz de verbalizar ordenadamente y que frecuentemente son referidas como una percepción trascendental de la experiencia. Disminuyen la memoria reciente y la capacidad de concentrarse y fijar la atención. Todos estos efectos dependen del estado emocional previo de la persona y del entorno en que se produce la experiencia. 
Efectos orgánicos: el LSD ejerce acciones de carácter simpático y anticolinérgico, produce síntomas y signos como midriasis (principal signo de intoxicación); cardiovasculares como taquicardia y aumento de la presión arterial; gastrointestinales (náuseas, vómitos y disminución del apetito); respiratorios (respiración más profunda con alteración del ritmo); y neurológicos con piloerección, temblores e hiperreflexia, así como aumento de la tensión muscular, pirexia, incoordinación y ataxia.

En animales, dosis muy altas de LSD pueden producir la muerte por insuficiencia respiratoria. La parada respiratoria está precedida por hipertermia, convulsiones y coma. En humanos son raros los fallecimientos por sobredosis, si se atiende rápidamente al intoxicado.

\section{d) Toxicidad aguda.}

La toxicidad aguda que puede producir el consumo de LSD se manifiesta por:

Reacciones psicóticas agudas. Los efectos psíquicos del LSD son a veces percibidos como extremadamente desagradables, constituyendo lo que se conoce como "mal viaje». Los malos viajes son difíciles de predecir, pues no aparecen exclusivamente con dosis altas. Son más frecuentes en sujetos con poca experiencia previa y en un entorno inadecuado. Generalmente son reacciones de ansiedad y disforia más o menos intensas, que pueden desembocar en accesos de pánico. A veces se presentan como psicosis francas, con alucinaciones verdaderas, acompañadas de desorientación y confusión. Suelen remitir en 8 a 12 horas sin necesidad de tratamiento específico. Basta tranquilizar al sujeto en un ambiente familiar y la administración de benzodiacepinas pueden ser útil.

Conducta violenta. Riesgo de suicidio. Aunque el LSD no fomenta conductas violentas y sus efectos sobre el comportamiento se traducen más bien en disminución de la agresividad, durante el viaje se reduce la capacidad de realizar juicios críticos sobre el alcance de los propios actos. Se conocen casos de suicidio en el curso de fantasías de omnipotencia o de trascendencia del universo humano, así como alguno de homicidio por sujetos que habían ingerido LSD.

\section{e) Tolerancia. Dependencia}

El consumo continuado de LSD provoca gran tolerancia a los efectos psicológicos. Existe tolerancia cruzada entre los diversos alucinógenos, pero no con las anfetaminas y los cannabinoides. Los alucinógenos del tipo LSD parece que carecen de acciones reforzadoras en otras especies. En la especie humana, en general, no ocasionan pautas de uso continuado durante períodos prolongados, lo más común consiste en consumos esporádicos, separados por intervalos de semanas o meses. Una de las razones para su uso esporádico es que la euforia no es constante y se trata más bien de un efecto secundario e infrecuente. El cese del consumo de alucinógenos no produce sintomatología de abstinencia.

\subsection{Indolalquilaminas y otros derivados indólicos}

Entre las indolalquilaminas están la psilocibina, la dimetiltriptamina (DMT) y la dietiltriptamina (DET).

La psilocibina se encuentra en los hongos Psilocybe mexicana Heim y Conocybe, que crecen en México y Centroamérica. Es la 4O-fosforil- dimetil triptamina. Es desfosforilada por la fosfatasa alcalina a su metabolito activo psilocina. Psilocibina a dosis de 60$200 \mu \mathrm{g} / \mathrm{kg}$ produce debilidad, náuseas, ansiedad, midriasis, visión borrosa, hiperrreflexia y alteraciones visuales como aumento del brillo de los colores, aumento de formas geométricas. Sus efectos son parecidos a los de la LSD pero de menor duración (2-6 horas) y de 150-200 veces menos potencia.

La DMT o dimetil triptamina es producida por plantas como Mimosa, Virola y Piptadenia, pero también puede ser obtenida sintéticamente, lo mismo que la dietiltriptamina 
(DET). La DMT no es activa por vía oral y, tradicionalmente, los productos vegetales que la contienen han sido utilizadas por indios sudamericanos. Sus efectos se instauran rápidamente y duran como máximo 30 ó 60 minutos. Su rapidez de instauración impide una adaptación progresiva del sujeto a los cambios psíquicos que ocasiona, lo que facilita la aparición de estados de pánico. Produce alteraciones de la percepción, alucinaciones visuales, midriasis e hipertensión arterial. La dosis habitual es de 50-100 mg.

DET o dietiltriptamina. Es un derivado sintético que se usa vía intramuscular. Produce efectos parecidos a la mescalina con estimulación simpática. Produce euforia y las alteraciones de la percepción son importantes. Puede producir cefalea, depresión e insomnio.

También son derivados indólicos la ibogaína, presente en la raíz de la planta africana Tabeernanthe Iboga apocinácea del Gabón, ha sido utilizado por los nativos africanos como alucinógeno y afrodisíaco; es hipotensor y anticolinesterásico. La harmina y la harmalina, alcaloides de plantas sudamericanas (Banisteriopsis caapı) que se encuentra en las cuencas del Amazonas y del Orinoco y en Oriente Medio (Peganum harmala). Estos alcaloides producen un temblor extrapiramidal.

La bufotenina $\circ \mathbf{N}$-dimetilserotonina es una alquil-hidroxi-triptamina que se aisla de las glándulas cutáneas del sapo (Bufo vulgaris) y de la planta mimosácea Piptadenia peregrina. Forma parte del cohoba, tabaco haitiano que contiene además DMT. A dosis bajas produce alteraciones visuales. Dosis de 1$20 \mathrm{mg}$ producen parestesias faciales, alucinaciones visuales, alteraciones en la percepción del tiempo y del espacio, náuseas, nistagmo y midriasis. Puede producir ceguera. La cáscara de plátano contiene derivados metilados de triptamina y serotonina con efectos alucinógenos leves cuando se inhalan.

\subsection{Feniletilaminas}

Los fármacos de este tipo tienen una estructura semejante a la anfetamina. Produ- cen, por tanto, marcados efectos físicos debidos a estimulación simpática, como taquicardia o aumento de la presión arterial además de efectos psíquicos psicoestimulantes tipo anfetamina, por ello su toxicidad es más elevada que la del LSD y los fármacos del grupo anterior y su capacidad de producir adicción acaso mayor. También se teme más la posibilidad de secuelas nerviosas. Entre ellos se encuentran la mescalina (el único natural, producida por distintos cactus americanos como el peyote).

La Mescalina es el principal alcaloide del Cactus Peyote, el cual contiene unos 18 alcaloides. Dicha planta es utilizada por los indios mejicanos en ritos religiosos así como para disminuir la fatiga y el hambre. Sus efectos son del orden de 4000 veces menos potente que la LSD, sus efectos están muy bien descritos en las obras de Aldous Huxley, "Las puertas de la percepción", "Cielo e infierno" y "La Isla". Las alucinaciones visuales consisten en colores brillantes, formas geométricas, animales y a veces formas humanas. Produce ansiedad, disminución de las funciones intelectuales y a dosis elevadas alteraciones del EEG. Es activa por vía oral, tiene una semivida de 6 horas y el $60-90 \%$ se excreta en orina sin metabolizar. Las dosis habituales son entre $200-500 \mathrm{mg}$.

\subsection{Anticolinérgicos y colinérgicos}

Diversas plantas contienen alcaloides anticolinérgicos. La atropina y escopolamina se encuentran en plantas como la mandrágora, belladona, estramonio, beleño, etc... tienen efectos centrales a dosis terapéuticas. A dosis altas tanto los efectos físicos como los psíquicos suelen ser muy desagradables. Se pierde de forma completa y duradera el contacto con la realidad, lo que produce sensación de miedo y hace que su consumo esté poco extendido, producen alucinaciones visuales, delirio y disartria.

La Amanita muscaria es un hongo ampliamente utilizado por los siberianos y mongoles. Sus principios activos son: la muscarina (alcaloide colinérgico), el muscimol y el 
ácido iboténico; estas dos últimas sustancias parecen ser las responsables de los efectos alucinógenos del hongo. Los efectos aparecen a los 15-20 minutos de la ingestión y duran hasta 4 horas. Los síntomas más frecuentes son entre otros: sueño anormal, visiones coloreadas y los efectos propios de un estímulo colinérgico.

\section{REFERENCIAS}

Abraham HD, Aldridge AM, Gogia P. (1996) The psychopharmacology of hallucinogens. Neuropsychopharmacology. 14, 285-98.

Aghajanian GK, Marek GJ. (1999) Serotonin and hallucinogens. Neuropsychopharmacology. 21, 16S-23S.

Battaglia G, Zaczek R, De Souza EB. "MDMA effects in brian: Pharmacologic profile and evidence of neurotoxicity from neurochemical and autoradiographic studies". En: Ecstasy: The clinical pharmacological and neurotoxicological effects of the drug MDMA. Norwell, Massachussets, Kluwer Academic Publishers, 151170, 1990.

Bobes J, Lorenzo P, Sáiz PA. (Eds.). Extasis (MDMA): Un abordaje comprehensivo. Ed. Masson, Barcelona, 1998.

Bobes J. (Ed.). Extasis: Aspectos Farmacológicos, Psiquiátricos y Médico-Legales. Ed. Neurociencias, Citrán, Barcelona, 1995.

Camí J. (Ed.). Farmacología y Toxicidad de la MDMA (Extasis). Ed. Neurociencias, Citrán, Barcelona, 1995.

Colado MI, Lorenzo P. "MDMA (Extasis): Farmacología y Toxicología". En: Extasis: Aspectos Farmacológicos, Psiquiátricos y Médico-Legales. Ed. Neurociencias, Citrán, Barcelona, 1-46, 1995.

Colado MI. "Neurotoxicidad inducida por MDMA y su prevención farmacológica", En: Extasis (MDMA): Un abordaje comprehensivo. Ed. Masson, Barcelona, 41-72, 1998.

Colado MI, Camarero J, Mechan AO, Sanchez V, Esteban B, Elliot JM, Green AR. (2001) A study of the mechanisms involved in the neurotoxic action of 3,4-methylenedioxymethamphetamine (MDMA, 'ecstasy') on dopamine neurones in mouse brain. $\mathbf{B r} \mathbf{J}$ Pharmacol. 134, 17111723.

Crowley TJ. "Trastornos relacionados con los alucinógenos." En: Kaplan HI, Sadock BJ (Eds). Tratado de PsiquiatríaNI (vol.2), Inter-médica, Buenos Aires, 784-790, 1997.

Grob CS. "Investigación humana con MDMA". En: Extasis (MDMA): Un abordaje comprehensivo. Ed. Masson, Barcelona, 90-105, 1998.

Lizasoain I, Moro MA, Martín del Moral M. "Alucinógenos". En: Lorenzo P, Ladero JM, Leza JC, Lizasoain I (Eds). Drogodependencias. Farmacología. Patología. Psicología. Legislación. $2^{2}$ Ed. Panamericana SA. Madrid. 2003. (en prensa).

Lorenzo P, Bobes J, Colado MI. “Drogas de diseño (I). MDMA (Extasis)." En: Lorenzo P, Ladero JM, Leza JC, Lizasoain I (Eds). Drogodependencias. Farmacología. Patología. Psicología. Legisla-

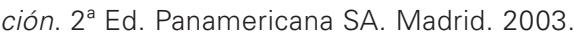
(en prensa).

Lorenzo P, Ladero JM, Bobes J. “Drogas de diseño (II). Otras feniletilaminas. Opioides. Otros.." En: Lorenzo P, Ladero JM, Leza JC, Lizasoain I (Eds). Drogodependencias. Farmacología. Patología. Psicología. Legislación. $2^{a}$ Ed. Panamericana SA. Madrid. 2003. (en prensa).

Lorenzo P. "MDMA y otras feniletilaminas. Farmacología y toxicología general." En: Extasis (MDMA): Un abordaje comprehensivo. Ed. Masson, Barcelona, 15-39, 1998.

Lorenzo P. (1994) Extasis (MDMA): Una droga de diseño de elevada toxicidad potencial. Anal Real Academia Nacional de Medicina. Tomo CXI. Cuaderno Tercero.

McCann UD, Ricaurte GA. "Aproximación a la neurobiología y neurotoxicidad comparada inducida por MDMA." En: Extasis (MDMA): Un abordaje comprehensivo. Ed. Masson, Barcelona, 89-97, 1998.

Miller DB, O'Callaghan JP. (1994) Environment-, drig- and stress-induced alterations in body temperature affect neurotoxicity of substituted amphetamines in the C57BL/6 J mouse. $\mathbf{J}$ Pharmacol Exp Ther. 270, 752-760.

Peroutka SJ (Ed). Ecstasy: The clinical, Pharmacological and Neurotoxicological Effects of the Drug MDMA. Kluwer Academic Publishers, Boston, 1990.

Ricaurte GA, Yuan J, Hatzidimitrou G, Cord BJ, McCann UD. (2002) Severe dopaminergic neu- 
rotoxicity in primates after a common recreational dose regimen of MDMA (Ecstasy). Science. 297, 2260-3.

Schuster CR, Lewis M, Seiden LS. (1986) Fenfluramine: neurotoxicity. Psychopharmacol Bull. 22, 148-151.

Sivilotti ML, Burns MJ, Aaron CK, Greenberg MJ. (2001) Pentobarbital for severe gamma-butyrolactone withdrawal. Ann Emerg Med 38, 660665.

Smith DE, Wesson DR, Buffum J. (1985) MDMA: "Ecstasy" as an adjunct to psychotherapy and a street drug of abuse. California Society for the Treatment of Alcoholism and Other Drug Dependences News 12, 1-3.

Steele TD, McCann UD, Ricaurte GA. (1994) 3,4methylene-dioxymethamphetamine (MDMA, "Ecstasy"): Pharmacology and toxicology in animals and humans. Addiction 89, 539-551.

Ungerleider JT, Pechnick RN. Alucinógenos. En: Galanter M, Kleber HD (Eds) Tratamiento de los trastornos por abuso de sustancias. Ed. Masson, Barcelona, 141-7, 1997. 
